\title{
Stabilization of Various Zero-Valent Metal Nanoparticles on a Superabsorbent Polymer for the Removal of Dyes, Nitrophenol, and Pathogenic Bacteria
}

Hani S.H. Mohammed Alia , Shahid Ali Khan ${ }^{\text {b* }}$

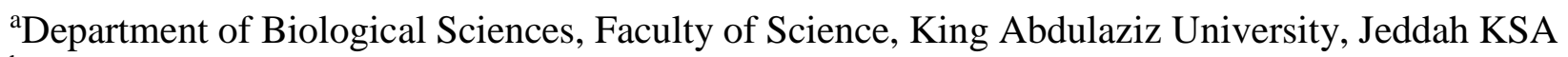

bepartment of Chemistry, University of Swabi, Swabi Anbar-23561, Khyber Pakhtunkhwa, Pakistan

*Corresponding

Dr. Shahid Ali Khan

Email: skhan@uoswabi.edu.pk 


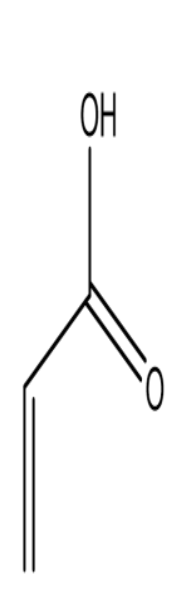

(a)

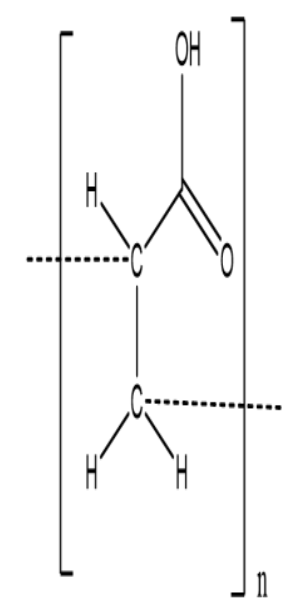

(b)

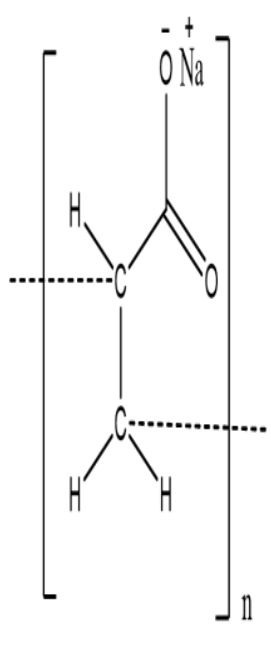

(c)

Figure S1: Chemical structure of acrylic acid (a), polyacrylic acid (b) and sodium polyacrylate (c).
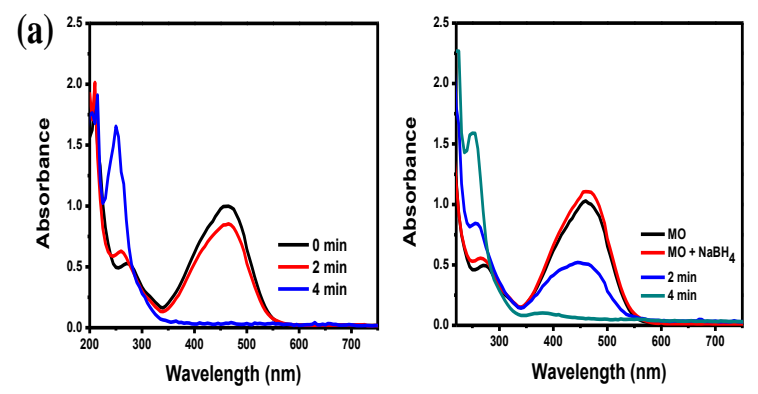

(b)
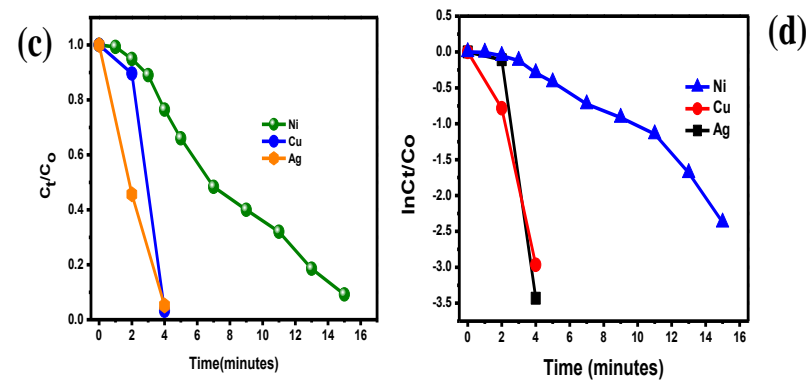

Figure S2: UV-vis. spectra of MO in the presence of WB loaded with Cu catalyst (a), $\mathrm{Ag}$ (b), and various kinetics parameters studied obtained from $\mathrm{C}_{t} / \mathrm{C}_{0}$ (c) and pseudo first order kinetics of WB loaded with $\mathrm{Ni}, \mathrm{Cu}$ and $\mathrm{Ag}$ NPs (d).

Experimental condition: $0.05 \mathrm{mM}$ of $2.5 \mathrm{~mL}$ of $\mathrm{MO}+1 \mathrm{mM}$ of $0.5 \mathrm{~mL}$ of $\mathrm{NaBH}_{4}$ solution and 20 $\mathrm{mg}$ of each catalyst. 

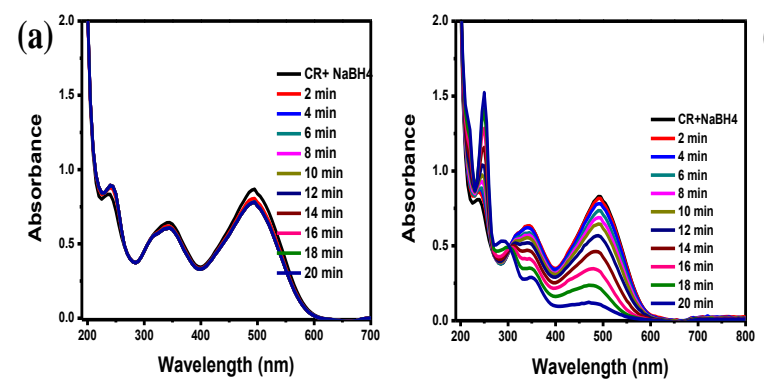

(b)
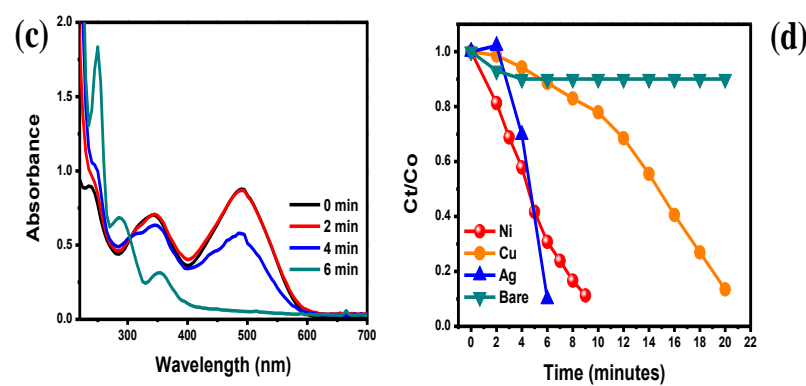

Figure S3: UV-vis spectra of $\mathrm{CR}$ in the presence $\mathrm{NaBH}_{4}$ and absence of catalyst (a), WB loaded with $\mathrm{Cu}$ catalyst (b), $\mathrm{Ag}$ (c), various kinetics parameters studied obtained from $\mathrm{C}_{\mathrm{t}} / \mathrm{C}_{0}(\mathrm{~d}) \mathrm{WB}$ loaded with $\mathrm{Ni}, \mathrm{Cu}$ and $\mathrm{Ag}$ NPs and bare (d).

Experimental condition: $0.05 \mathrm{mM}$ of $2.5 \mathrm{~mL}$ of $\mathrm{CR}+1 \mathrm{mM}$ of $0.5 \mathrm{~mL}^{\circ} \mathrm{NaBH}_{4}$ solution and 20 mg of each catalyst.
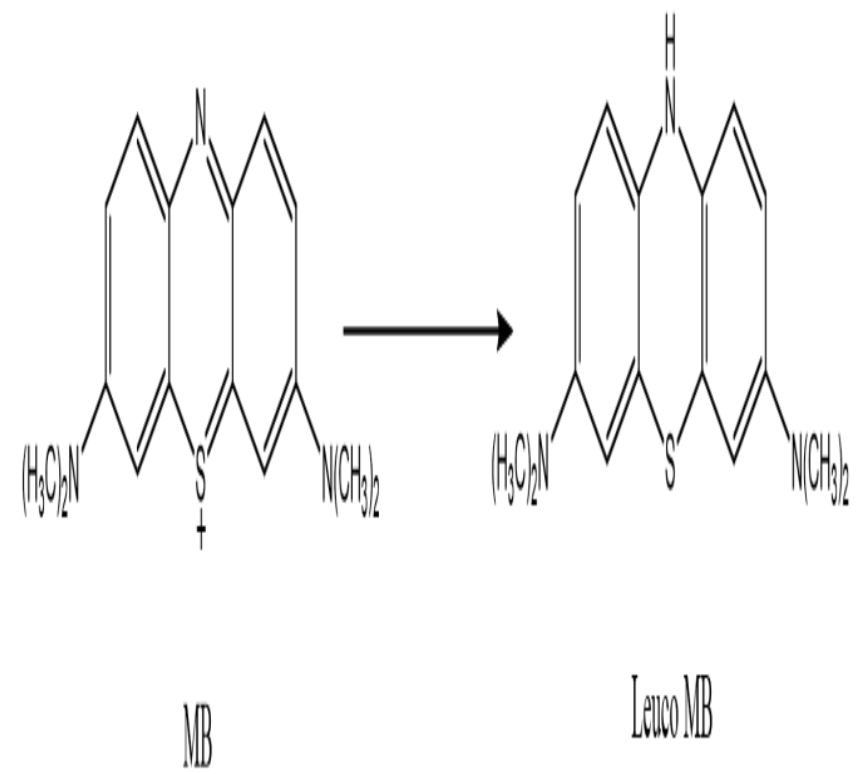

Figure S4: structure of MB and leuco MB. 